\title{
Erratum to: Deconstructing the "July Effect" in Operative Outcomes: A National Study
}

\author{
Ammara A. Watkins ${ }^{1} \cdot$ Lindsay A. Bliss $^{1} \cdot$ Danielle B. Cameron ${ }^{2}$. \\ Mariam F. Eskander ${ }^{1} \cdot$ Jennifer F. Tseng ${ }^{1}$. Tara S. Kent ${ }^{1}$
}

Published online: 9 June 2016

(C) 2016 The Society for Surgery of the Alimentary Tract

\section{Erratum to: J Gastrointest Surg}

DOI: 10.1007/s11605-016-3120-4

Dr. Mariam F. Eskander's name was inadvertently omitted from the author byline for the article Deconstructing the "July Effect" in Operative Outcomes: A National Study, which was published in the May issue of Journal of Gastrointestinal surgery.

The full author byline should read:

Ammara A. Watkins, Lindsay A.Bliss, Danielle B. Cameron, Mariam F. Eskander, Jennifer F. Tseng, Tara S. Kent

Dr. Eskander made substantial contributions to the design, analysis and interpretations of statistical work as part of the revised, final manuscript. She also critically reviewed and revised the final submitted manuscript and was agreeable to all aspects of the work and agreed to be accountable to all aspects of the final submitted work including accuracy and integrity. Dr. Eskander has no conflicts of interest to disclose.

The online version of the original article can be found at http://dx.doi.org/ 10.1007/s11605-016-3120-4.

Ammara A. Watkins

aawatkin@bidmc.harvard.edu

Beth Israel Deaconess Medical Center, 330 Brookline Ave. Stoneman 9, Boston, MA 02215, USA

2 Boston Children's Hospital, 300 Longwood Ave., Boston, MA 02115, USA 